\title{
Efeito dos ácidos graxos essenciais sobre lipidemia e vascularização da membrana vitelina de codornas japonesas
}

\author{
[Effect of essential fatty acids on lipidemia and vitelline membrane \\ vascularization in Japanese quails] \\ J.E.S. Silva ${ }^{1}$, A.M.A. Moura ${ }^{2}$, R.A. Nogueira ${ }^{1 *}$ \\ ${ }^{1}$ Programa de pós-graduação - Universidade Federal Rural de Pernambuco - Recife, PE \\ ${ }^{2}$ FIOCRUZ - Recife, PE
}

\begin{abstract}
RESUMO
Verificou-se o efeito de diferentes fontes de ácidos graxos essenciais ômega-3 e ômega-6 sobre o perfil lipídico de codornas japonesas e sobre o crescimento vascular na membrana vitelina dos embriões de aves suplementadas com óleo de peixe, $2 \%$ e $4 \%$, e óleo de soja, $2 \%$ e $4 \%$, em relação à dieta-controle, sem suplementação lipídica. Foi usado o método enzimático com reação colorimétrica para estimar o perfil lipídico sérico de colesterol total, triglicerídeos e HDL das aves. A vascularização na membrana vitelina foi quantificada por meio da dimensão fractal, utilizando-se o método de box-counting. A concentração de colesterol dos grupos controle e tratados não diferiu entre si. Para o HDL, o grupo que recebeu maior proporção de óleo de peixe, $4 \%$, diferiu dos outros grupos. Os níveis de triglicerídeos das codornas suplementadas com óleo de peixe foram superiores aos dos demais grupos. A dimensão fractal da vascularização da membrana vitelina dos embriões de codornas dos grupos que receberam $4 \%$ de óleo de peixe e $4 \%$ de óleo de soja foi significativamente menor que a dos demais grupos, indicando efeitos antiangiogênicos no processo de formação vascular.
\end{abstract}

Palavras-chave: codorna, ácidos graxos, codorna japonesa, fractal, membrana vitelina, vascularização

\begin{abstract}
The effect of different sources of omega-3 and omega-6 essential fatty acids on serum lipid profile in Japanese quails and on vascular growth in the embryos vitelline membrane was verified. The birds were supplemented with fish oil, $2 \%$ and $4 \%$, and soybean oil, $2 \%$ and $4 \%$, and one control diet, without lipid supply. The enzymatic method with colorimetric reaction was used to estimate the profile of serum total cholesterol, triglycerides and HDL of the birds. Vitelline membrane vascularization was measured using the box-counting fractal dimension. The cholesterol concentration of the treated and control groups showed no difference. For HDL, the group treated with a higher proportion of fish oil, 4\%, differed from other groups. The triglycerides levels of quails supplemented with fish oil were higher than the other groups. The fractal dimension of quail embryos vitelline membrane from the groups treated with $4 \%$ fish oil and 4\% soybean oil was lower than the other groups, indicating antiangiogenic effects on the vascular formation process.
\end{abstract}

Keywords: fatty acids, fractal, japanese quail, vitelline membrane, vascularization

\section{INTRODUÇÃO}

O ômega-3 (n-3) e o ômega-6 (n-6) são ácidos graxos essenciais que participam de diversas funções metabólicas. Além disso, doenças crônicas como hipertensão, diabetes, câncer e desordens autoimunes são frequentemente associadas com anormalidades no metabolismo dos ácidos graxos poliinsaturados, o que tem despertado o interesse acerca dos possíveis benefícios do consumo destes compostos à

Recebido em 24 de maio de 2011

Aceito em 20 de julho de 2012

*Autor para correspondência (corresponding author)

E-mail: ran.pe@terra.com.br 
saúde, dentre eles, alterações nos níveis de colesterol total, colesterol HDL e triglicerídeos e prevenção de diversas patologias.

Os ácidos graxos poliinsaturados (PUFA, do inglês polyunsaturated fatty acids) que compõem a família n-6 são derivados do ácido linoleico, sendo encontrados na maioria das sementes e vegetais, como milho, girassol, açafrão e soja, enquanto os da família n-3, derivados do ácido $\alpha$ linolênico, podem ser encontrados nos óleos de canola, linhaça, na noz, nas plantas com coloração verde-escura e nos óleos de peixe, principalmente naqueles provenientes das regiões polares (Calder, 1996).

Diversos efeitos de suplementação alimentar com PUFA foram observados em aves (Murata et al., 2003; Navidshad et al., 2010), ratos (Molena-Fernandes et al., 2010) e humanos (Dewailly et al., 2001; 2003) sobre o perfil lipídico sérico de colesterol total, triglicerídeos e lipoproteína de alta densidade (HDL). A HDL possui a capacidade de interagir com as células na vascularização sistêmica, revertendo a disfunção celular do endotélio, estimulando a produção de prostaciclinas, diminuindo a agregação plaquetária, inibindo a apoptose celular do endotélio e a oxidação do LDL, bem como apresentando efeito antiaterogênico, entre outras funções (Toth, 2004).

O sistema vascular está envolvido no crescimento e na proliferação celular normal e patológica, nos processos de reparação de tecidos e nos distúrbios circulatórios. Este sistema responde diretamente a fatores estimulantes, moduladores e inibitórios, com remodelagem da vascularização. $\mathrm{Na}$ vascularização é possível distinguir dois diferentes mecanismos de formação de novos vasos sanguíneos: a vasculogênese e a angiogênese (Conway et al., 2001). Na vasculogênese, angioblastos e hemangioblastos coalescem e se diferenciam em células endoteliais, formando uma rede vascular primitiva. O remodelamento dessa rede ocorre por meio da angiogênese, que envolve brotamento, intussuscepção e/ou ligação, resultando na formação de microvasos (Hendrix et al., 2003).

Os ácidos graxos interferem em diversas etapas do processo de formação vascular, por meio dos derivados dos eicosanoides e do ácido aracdônico (Calder, 2003; O'Shea, 2004), cujos efeitos podem ser pró (Naraynan et al., 2003; Cianchi et al., 2003; 2004) ou antiangiogênicos (Harris et al., 2009). A proliferação de células endoteliais vasculares, bem como a migração e formação de capilares, é estimulada por fatores de crescimento angiogênico, os quais incluem as proteínas do VEGF, TGF- $\beta$ e eicosanóides que derivam dos ácidos graxos poliinsaturados n-6 (Dewailly et al., 2001; 2003).

$\mathrm{Na}$ avaliação do processo de crescimento vascular, têm sido utilizados modelos in vivo, como a membrana vitelina (MV) de embriões de aves, devido a sua acessibilidade à observação e à experimentação. A MV é formada por secreções emitidas pelo epitélio folicular $\mathrm{e}$ oviduto, constituindo uma membrana interna e outra uma externa (Chung et al., 2010), sendo o local onde ocorre a eritropoiese inicial do saco vitelino, no mesoderma extraembrionário, antes da expansão do celoma extraembrionário e da invasão do alantóide, e neste contexto, abrange as três camadas germinativas (Sheng, 2010).

Um modo de verificar alterações na estrutura vascular é pela avaliação de sua complexidade, por meio da quantificação do crescimento dos vasos utilizando-se a geometria fractal. $\mathrm{O}$ termo fractal (do radical fractus) foi cunhado por Mandelbrot (1991), que reuniu, criou e popularizou uma grande coleção de objetos caracterizados por suas propriedades, que são: $i$ ) autossimilaridade, a qual significa que partes de um objeto ou processo parecem com o objeto ou com o processo todo; ii) dependência de escala (scaling), o que significa dizer que a medida da grandeza depende da escala na qual foi medida; iii) dimensão fractal, a qual provê uma descrição quantitativa da autos-similaridade e dependência de escala (Bassingthwaighte et al., 1994) e reflete as irregularidades na forma dos objetos ou processos fractais.

A geometria fractal constitui uma ferramenta que possibilita a quantificação de processos complexos como a rede vascular. Por outro lado, dietas enriquecidas com n-3 e n-6 têm sido investigadas quanto a sua utilização para prevenção, tratamento e controle de patologias associadas ao crescimento vascular, podendo ser usadas com fins terapêuticos e trazendo benefícios à saúde da população. Assim, este estudo teve como objetivo verificar efeitos da 
suplementação com n-3 e n-6 sobre o perfil lipídico de codornas e analisar, usando a dimensão fractal, o processo de vascularização da membrana vitelina dos embriões dessas aves.

\section{MATERIAIS E MÉTODOS}

Foram selecionadas 80 codornas japonesas (Coturnix japonica) de 60 dias de idade, 60 fêmeas e 20 machos. As codornas foram pesadas e distribuídas em delineamento em blocos inteiramente ao acaso, com cinco tratamentos e quatro repetições com quatro aves por unidade experimental (1 macho: 3 fêmeas). As codornas foram alojadas em gaiolas metálicas $(100 \times 30 \times 20 \mathrm{~cm})$, sobrepostas em cinco andares com quatro gaiolas por andar. Cada gaiola foi equipada com comedouro e bebedouro tipo calha e bandeja coletora de excretas. As aves foram alimentadas com ração comercial ad libitum e água fresca, sendo mantidas sob um programa de luz artificial claro/escuro de 17/5 horas durante 63 dias. O protocolo experimental foi realizado em conformidade com os procedimentos descritos no protocolo n. 23082.005779/2011 do Comitê de Ética para o Uso de Animais (CEUA/ UFRPE).

Os grupos testados foram constituídos por quatro dietas experimentais, isoproteicas e isocalóricas, e uma dieta-controle, formuladas de acordo com as exigências para codornas em postura segundo o NRC (National..., 1994), com exceção do cálcio, cuja recomendação foi a de Pereira et al. (2004). Foi utilizado o valor de energia metabolizável aparente do milho, farelo de soja, farelo de trigo e óleo de soja, obtidos por Moura et al. (2010). Para formulação das dietas, utilizou-se o software SuperCrac, v.5.4 da TDNet, Viçosa, MG (2002). A composição centesimal e nutricional das dietas experimentais encontra-se na Tab. 1. Os grupos experimentais foram distribuídos e receberam a seguinte denominação: dieta-controle (DC), óleo de peixe $2 \%$ (OP 2\%), óleo de peixe 4\% (OP 4\%), óleo de soja $2 \%(\mathrm{OS} 2 \%)$ e óleo de soja $4 \%$ (OS $4 \%$ ).

Após o período de adaptação, iniciou-se a coleta dos ovos das aves, realizada duas vezes ao dia, sendo a primeira no início da manhã e a segunda no final da tarde. Os ovos de cada parcela foram contabilizados e identificados de acordo com o grupo experimental. Para a incubação, foram selecionados ovos com formato regular e casca íntegra. Os ovos foram incubados a $37,5^{\circ} \mathrm{C}$, com a umidade relativa em torno de $60 \%$. Após 24 horas de incubação, realizou-se a desinfecção da casca dos ovos e, em seguida, uma janela $(2,0 \times 2,0 \mathrm{~cm}$, aproximadamente) foi feita com tesoura esterilizada, para remoção de $1 \mathrm{~mL}$ de albúmen para melhor visualização da membrana vitelina, bem como de sua vascularização. Após a retirada do albúmen, a janela foi selada com parafilme para evitar desidratação do embrião.

Entre 72 e 120 horas de incubação, imagens da rede vascular da membrana vitelina (MV) foram capturadas com câmera digital (1920 x 1980 pixels) em intervalos de 24 horas. Em seguida, foi realizada a segmentação e esqueletização da vascularização da MV. A segmentação consiste em extrair a imagem dos vasos sanguíneos da imagem da MV. Nesta segmentação foi usada a dimensão de um pixel para todos os vasos, processo denominado esqueletização, considerado um indicador muito sensível de alterações na distribuição vascular (ParsonsWingerter et al., 1998; Avakian et al., 2002). As imagens das membranas vitelinas foram segmentadas e esqueletizadas usando-se uma rotina computacional semiautomática (Fig. 1), como descrito em Kunicki et al. (2009).

Para avaliar os efeitos dos PUFA n-3 e n-6 no metabolismo lipídico, no $63^{\circ}$ dia experimental, as aves foram submetidas a jejum alimentar de $12 \mathrm{~h}$ $\mathrm{e}$, em seguida, foi colhido $1 \mathrm{~mL}$ de sangue das aves ( $n=4 /$ repetição) por meio de punção da veia braquial da asa. $\mathrm{O}$ material foi colhido em tubos devidamente identificados, sem anticoagulante. Após, as amostras foram centrifugadas a $4000 \mathrm{x}$ $\mathrm{g}$, durante 15 minutos, para obtenção do soro. Posteriormente, separaram-se as alíquotas necessárias às dosagens das concentrações plasmáticas do colesterol (CT), colesterol HDL e triglicerídeos (TG). As absorbâncias delas foram analisadas em triplicata, por reação enzimática de ponto final com reação colorimétrica (kits comerciais Labtest Diagnóstica SA, Belo Horizonte, MG, Brasil) em espectrofotômetro de luz ultravioleta visível. 
Silva et al.

Tabela 1. Composição centesimal e nutricional das dietas experimentais para codornas em fase de postura segundo os tratamentos

\begin{tabular}{|c|c|c|c|c|c|}
\hline Ingrediente & $\mathrm{DC}$ & OP $2 \%$ & OP $4 \%$ & OS $2 \%$ & OS $4 \%$ \\
\hline Milho & 54,36 & 54,78 & 54,66 & 54,78 & 54,66 \\
\hline Farelo de soja & 34,20 & 31,49 & 31,66 & 31,49 & 31,66 \\
\hline Farelo de trigo & 0,00 & 0,39 & 0,00 & 0,39 & 0,00 \\
\hline Óleo de peixe & 0,00 & 2,00 & 4,00 & 0,00 & 0,00 \\
\hline Óleo de soja & 0,00 & 0,00 & 0,00 & 2,00 & 4,00 \\
\hline Calcário calcítico & 6,20 & 6,48 & 6,47 & 6,48 & 6,47 \\
\hline Fosfato bicálcico & 2,01 & 1,60 & 1,60 & 1,60 & 1,60 \\
\hline Suplemento vitamínico e mineral ${ }^{(1)}$ & 0,50 & 0,50 & 0,50 & 0,50 & 0,50 \\
\hline DL-metionina & 0,17 & 0,20 & 0,20 & 0,20 & 0,20 \\
\hline L-lisina & 0,02 & 0,11 & 0,11 & 0,11 & 0,11 \\
\hline Sal comum & 0,53 & 0,46 & 0,28 & 0,46 & 0,28 \\
\hline Inerte & 2,00 & 2,00 & 0,52 & 2,00 & 0,52 \\
\hline Antioxidante $^{(2)}$ & 0,01 & 0,01 & 0,01 & 0,01 & 0,01 \\
\hline Total & 100 & 100 & 100 & 100 & 100 \\
\hline \multicolumn{6}{|c|}{ Valor nutricional calculado } \\
\hline Proteína bruta (\%) & 19,00 & 19,00 & 19,00 & 19,00 & 19,00 \\
\hline Energia metabolizável (kcal/kg) & 2.800 & 2.800 & 2.800 & 2.800 & 2.800 \\
\hline Cálcio $(\%)$ & 3,00 & 3,00 & 3,00 & 3,00 & 3,00 \\
\hline Cloro $(\%)$ & 0,34 & 0,30 & 0,00 & 0,30 & 0,19 \\
\hline Sódio (\%) & 0,25 & 0,22 & 0,15 & 0,22 & 0,15 \\
\hline Fósforo disponível (\%) & 0,48 & 0,40 & 0,40 & 0,40 & 0,40 \\
\hline Fósforo total (\%) & 0,70 & 0,62 & 0,00 & 0,62 & 0,61 \\
\hline Lisina total $(\%)$ & 1,10 & 1,10 & 1,10 & 1,10 & 1,10 \\
\hline Metionina + cisteína $(\%)$ & 0,80 & 0,80 & 0,80 & 0,80 & 0,80 \\
\hline Metionina total (\%) & 0,48 & 0,49 & 0,00 & 0,49 & 0,49 \\
\hline Treonina total (\%) & 1,32 & 1,23 & 1,23 & 1,23 & 1,23 \\
\hline Triptofano total (\%) & 0,25 & 0,24 & 0,24 & 0,24 & 0,24 \\
\hline
\end{tabular}

${ }^{1}$ Níveis de garantia por quilo do produto: vit. A (8000000UI), vit. D3 (2000000UI), vit. E (15000mg), vit. K3 (1960mg), vit. B2 (4000mg), vit. B6 (1000mg), vit. B12 (100000mcg), niacina (19800mg), ác. pantotênico (5350mg), ác. fólico (200mg), Mn (32500mg), Zn (50000mg), Fe (20000mg), Cu (4000mg), I (1500mg), Se (250mg), Co (200mg), antioxidante (100000mg). ${ }^{2}$ Antioxidante Butil-hidroxitolueno (BHT).

DC: dieta-controle; OP 2\%: óleo de peixe $2 \%$; OP $4 \%$ : óleo de peixe $4 \%$; OS $2 \%$ : óleo de soja 2\%; OS 4\%: óleo de soja $4 \%$.
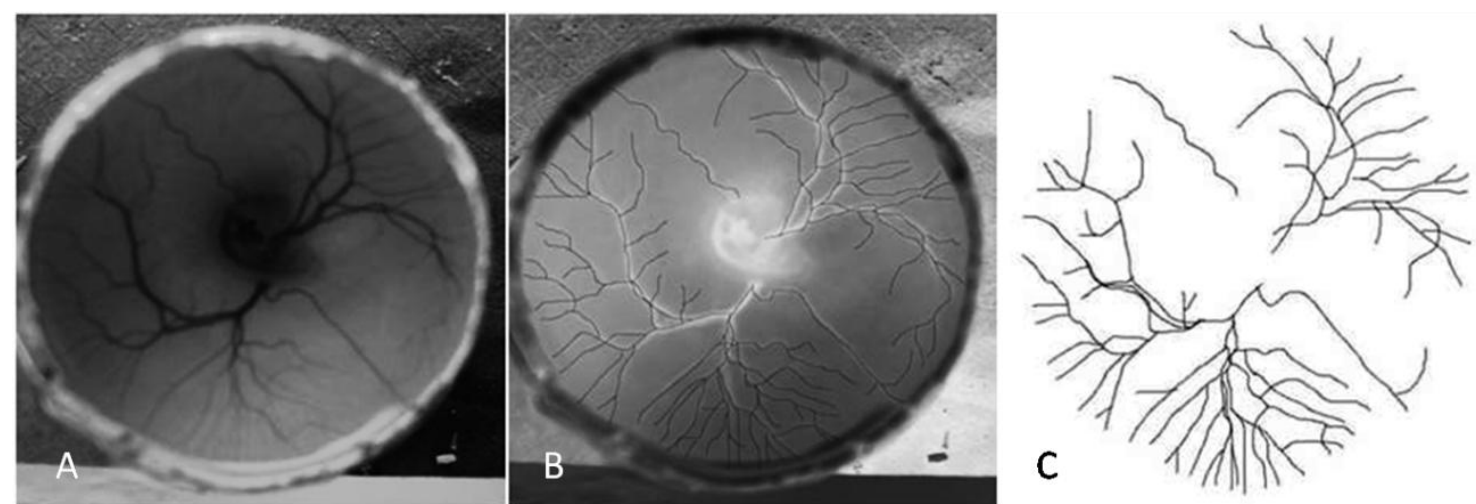

Figura 1. Processo de segmentação e esqueletização da imagem de vascularização da MV de embriões de codorna japonesa. A - rede vascular da MV; B - obtenção do negativo da imagem, com destaque da vascularização em contraste com o fundo da imagem e segmentação dos vasos da MV; C - binarização e esqueletização da imagem, para obtenção de padrão em preto e branco. 
A análise estatística foi realizada aplicando-se o teste de Kolmogorov-Smirnov para verificar a normalidade da distribuição dos dados obtidos (P>10\%). Como os dados apresentaram distribuição gaussiana, realizou-se uma análise de variância e aplicou-se o teste post-hoc de Tukey $(\alpha=5 \%)$.

\section{RESULTADOS E DISCUSSÃO}

Não houve diferença significativa entre os grupos experimentais para a variável colesterol total. Porém, para as variáveis HDL e triglicerídeos totais, a concentração sérica destes componentes lipídicos foi influenciada pelas dietas experimentais, conforme descrito na Tab. 2.

Tabela 2. Valores médios obtidos para colesterol total (CT), HDL e triglicerídeos (TG) no sangue de codornas submetidas a diferentes dietas

\begin{tabular}{llccc}
\hline & & & Parâmetros avaliados & \\
Tratamento & & CT $(\mathrm{mmol} / \mathrm{L})$ & HDL $(\mathrm{mmol} / \mathrm{L})$ & TG $(\mathrm{mmol} / \mathrm{L})$ \\
\hline DC & A & $11,20 \pm 3,15$ & $1,93 \pm 0,86 \mathrm{c}$ & $6,49 \pm 0,80 \mathrm{bc}$ \\
OP 2\% & B & $13,30 \pm 10,60$ & $1,89 \pm 1,10 \mathrm{c}$ & $22,72 \pm 16,59 \mathrm{ade}$ \\
OP 4\% & $\mathrm{C}$ & $13,57 \pm 5,46$ & $5,20 \pm 4,86 \mathrm{abde}$ & $25,54 \pm 17,19 \mathrm{ade}$ \\
OS 2\% & $\mathrm{D}$ & $12,24 \pm 3,20$ & $2,05 \pm 0,87 \mathrm{c}$ & $5,90 \pm 2,41 \mathrm{bc}$ \\
OS 4\% & $\mathrm{E}$ & $14,10 \pm 1,92$ & $2,01 \pm 0,52 \mathrm{c}$ & $10,75 \pm 7,65 \mathrm{bc}$ \\
Teste F & & $6,935^{\mathrm{NS}}$ & $6,299^{*}$ & $10,743^{*}$ \\
P & & $>0,05$ & 0,0002 & 0,0001 \\
\hline
\end{tabular}

Letras em sobrescrito nos parâmetros (CT, HDL e TG) obtidos em cada tratamento referem-se às diferenças significativas em relação aos demais tratamentos (teste de Tukey). *Diferença significativa entre os grupos. NS Diferença não significativa. DC: dieta-controle; OP 2\%: óleo de peixe 2\%; OP 4\%: óleo de peixe 4\%; OS 2\%: óleo de soja $2 \%$; OS $4 \%$ : óleo de soja $4 \%$.

Güçlü et al. (2008), suplementando codornas japonesas com diferentes fontes lipídicas, observaram menores níveis de colesterol total sérico nas aves que receberam $4 \%$ de óleo de soja quando comparadas às aves suplementadas com $4 \%$ de óleo de peixe. A presença de esteróis vegetais não permite a entrada ou o deslocamento do colesterol para as micelas intestinais, impedindo parcialmente sua absorção e reduzindo, consequentemente, os valores totais de colesterol. Estes resultados discordam dos encontrados no presente experimento, em que as aves que não receberam fonte de ácido graxo poliinsaturado (PUFA) de origem animal apresentaram níveis séricos de colesterol total (CT) semelhantes àquelas que receberam dietas enriquecidas com óleo de peixe. Os lipídios séricos podem provir da absorção intestinal dos lipídios ingeridos, da mobilização dos lipídios decorrente de estocagem no tecido adiposo ou de processos metabólicos. A quantidade e o tipo de alimento, entre outros fatores, influenciam as concentrações lipídicas no plasma. Dada a importância do colesterol nas diversas funções metabólicas, mesmo quando este não é disponibilizado na dieta, o organismo cria alternativas para sua síntese de novo, por meio do transporte reverso do colesterol.
Resultados semelhantes foram observados por Raber et al. (2008) e Murata et al. (2003), que não observaram alteração nos níveis séricos de CT em frangos de corte suplementados com até $5 \%$ de óleo ácido ou óleo de soja. Navidshad et al. (2010) verificaram aumento do colesterol total sérico de frangos de corte suplementados com $7 \%$ de óleo de soja em relação às aves suplementadas com 3,5\% de óleo de soja e 3,5\% de óleo de peixe. Entretanto, não houve diferença neste parâmetro quando comparado ao das aves suplementadas com $7 \%$ de óleo de peixe.

Em poedeiras comerciais, a adição de óleo de peixe em concentrações de $0,5 \%$ a $4 \%$ não altera os níveis séricos de CT quando estes são comparados ao grupo-controle (Mendonça Jr. et al., 2000). Resultados semelhantes foram observados por Fanchiotti et al. (2010), quando a adição de óleo de soja e/ou linhaça em concentrações de $2 \%$ não alterou o perfil lipídico e o colesterol total sérico de poedeiras leves e semipesadas. De acordo com os autores, o metabolismo lipídico é mais acelerado em poedeiras leves quando comparado ao metabolismo das semipesadas, uma vez que as primeiras exigem maior mobilização de ácidos 
graxos e hormônios esteroides para síntese de gema.

A inclusão do óleo de peixe na dieta promoveu aumento direto na concentração sérica do HDL e dos triglicerídeos totais nas aves, em relação aos grupos que receberam fonte lipídica vegetal. $\mathrm{O}$ grupo OP 4\% apresentou maior concentração de colesterol HDL em relação aos demais tratamentos, efeito anteriormente observado em frangos de corte por Navidshad et al. (2010), e em humanos, por Dewailly et al. (2003). Entretanto, Güçlü et al. (2008) não verificaram efeito de diferentes PUFA sobre o colesterol HDL de codornas suplementadas com óleo de soja ou de peixe em concentrações de $4 \%$. Resultado semelhante foi observado em poedeiras comerciais (Mendonça Jr. et al., 2000), nas quais a suplementação com óleo de peixe em concentrações de até $4 \%$ não modificou a concentração sérica de colesterol HDL em comparação às aves do grupo- controle. Esta lipoproteína possui papel fundamental no transporte do excesso de colesterol dos tecidos extra-hepáticos de volta para o fígado (transporte reverso do colesterol).

No presente experimento, a concentração de TG foi elevada nas aves dos grupos OP $2 \%$ e OP $4 \%$, quando comparada à das aves dos grupos OS $2 \%$ , OS $4 \%$ e DC. Este efeito pode ser decorrente de um maior tempo de absorção das frações lipídicas do óleo de peixe pelo trato intestinal, colaborando para maior concentração destes componentes no sangue. Güçlü et al. (2008) não verificaram efeito da suplementação com $4 \%$ de óleo de soja ou de peixe sobre o triglicerídeo sérico de codornas japonesas. Em frangos de corte, Raber et al. (2008) verificaram que a suplementação com 4 e 5\% de óleo ácido ou óleo de soja elevou os níveis de TG séricos. Entretanto, Navidshad et al. (2010) não verificaram efeito da suplementação com n-3 ou n-6 sobre este parâmetro.

Resultados semelhantes foram observados em poedeiras comerciais suplementadas com óleo de peixe (Mendonça Jr. et al., 2000) e em poedeiras leves e semipesadas recebendo óleo de soja e/ou de linhaça na ração (Fanchiotti et al., 2010), cujas as diferentes fontes de PUFA não alteraram os níveis de TG das aves. A quantidade e o tipo de alimento, entre outros fatores, influenciam as concentrações lipídicas no plasma. As concentrações de triglicerídeos podem variar muito, estando, em grande parte, relacionadas à ingestão dietética, estocagem ou mobilização dos tecidos adiposos e da síntese no fígado.

De maneira geral, no metabolismo lipídico, o ômega-3 provoca redução dos triglicérides séricos pela diminuição da síntese hepática de lipoproteínas de muito baixa densidade (VLDL) e apolipoproteína $\mathrm{B}$, aumento do colesterol da lipoproteína de alta densidade (HDL-colesterol) e aumento do LDL-colesterol, porém essas alterações são dependentes dos valores basais e dos níveis de suplementação de ômega-3 na dieta.

Para a quantificação do processo de crescimento vascular na membrana vitelina, os valores médios da dimensão fractal obtidos por dimensão de box-counting $\left(\mathrm{D}_{b c}\right)$ são apresentados na Tab. 3.

Tabela 3. Dimensão fractal $(\mathrm{M} \pm \mathrm{SD})$ obtida pelos métodos de box-counting (Dbc) para os diferentes tratamentos em distintos tempos de incubação

\begin{tabular}{|c|c|c|c|c|c|c|c|}
\hline \multirow{2}{*}{\multicolumn{2}{|c|}{ Tratamento }} & \multicolumn{2}{|r|}{$72 \mathrm{~h}$} & \multicolumn{2}{|r|}{$96 \mathrm{~h}$} & \multicolumn{2}{|r|}{$120 \mathrm{~h}$} \\
\hline & & $\mathrm{N}$ & $\mathrm{D}_{b c}$ & $\mathrm{n}$ & $\mathrm{D}_{b c}$ & $\mathrm{~N}$ & $\mathrm{D}_{b c}$ \\
\hline $\mathrm{DC}$ & $\mathrm{A}$ & 31 & $1,25 \pm 0,06 \mathrm{e}$ & 14 & $1,31 \pm 0,06 \mathrm{e}$ & 7 & $1,34 \pm 0,04$ \\
\hline OP $2 \%$ & B & 19 & $1,23 \pm 0,06$ & 19 & $1,29 \pm 0,05 \mathrm{e}$ & 14 & $1,30 \pm 0,06$ \\
\hline OP $4 \%$ & $\mathrm{C}$ & 24 & $1,21 \pm 0,04 \mathrm{~d}$ & 19 & $1,27 \pm 0,04$ & 9 & $1,29 \pm 0,03$ \\
\hline OS $2 \%$ & $\mathrm{D}$ & 24 & $1,26 \pm 0,06 \mathrm{ce}$ & 17 & $1,27 \pm 0,06$ & 9 & $1,32 \pm 0,04$ \\
\hline OS $4 \%$ & $\mathrm{E}$ & 25 & $1,20 \pm 0,04 \mathrm{ad}$ & 16 & $1,23 \pm 0,05 \mathrm{ab}$ & 11 & $1,27 \pm 0,04$ \\
\hline Teste F & & & $6,028 *$ & & $5,146^{*}$ & & $3,531^{\mathrm{NS}}$ \\
\hline $\mathrm{P}$ & & & 0,0002 & & 0,0010 & & 0,0137 \\
\hline
\end{tabular}

Letras em sobrescrito na dimensão fractal obtida em cada tratamento referem-se às diferenças significativas em relação aos demais tratamentos (teste de Tukey). *Diferença significativa entre os grupos. ${ }^{\text {NS }}$ Diferença não significativa. DC: dieta-controle; OP $2 \%$ : óleo de peixe $2 \%$; OP $4 \%$ : óleo de peixe $4 \%$; OS $2 \%$ : óleo de soja $2 \%$; OS $4 \%$ : óleo de soja $4 \%$. 
Em 72 horas de incubação, a vascularização da MV no grupo OS $4 \%$ foi inferior à vascularização das $\mathrm{MV}$ dos grupos $\mathrm{DC}(\mathrm{P}<0,01)$ e OS $2 \%(\mathrm{P}<0,001)$. A vascularização da MV no grupo OP $4 \%$ foi inferior apenas quando comparada ao grupo OS $2 \%(\mathrm{P}<0,05)$. Os demais grupos não apresentaram diferença significativa entre si $(\mathrm{P}>0,05)$. Em 96 horas de incubação, a vascularização da MV dos embriões das aves do grupo OS $4 \%$ foi inferior à vascularização das MV dos grupos OP $2 \%(\mathrm{P}<0,5)$ e DC $(\mathrm{P}<0,01)$, não sendo observada diferença significativa entre os demais grupos. Estas variações podem indicar que as diferentes concentrações e tipos de PUFA utilizados nas rações interferiram nos estágios iniciais de formação da rede vascular na membrana extraembrionária e que, como proposto por Harris et al. (2009), o metabolismo dos ácidos graxos n-3 e n-6 geraram compostos com efeito antiangiogênico.

Embora os PUFA n-6 estejam relacionados com a expressão da enzima óxido nítrico sintase induzida (iNOS) (Narayanam et al., 2003), que apresenta correlação positiva com a expressão da cicloxigenase 2 (COX-2) e com a angiogênese (Cianchi et al., 2003; 2004), o AA e o AL podem dar origem a moléculas anti-inflamatórias, como, por exemplo, nas células que formam o revestimento dos vasos sanguíneos, suprimindo a produção de moléculas de adesão, quimiocinas e interleucinas (Harris et al., 2009).

Em 120 horas de incubação não houve diferença significativa entre os grupos $(\mathrm{P}>0,05)$, concordando com o que foi proposto por Vico et al. (1998), os quais sugerem que, após 100 horas de incubação, a complexidade da rede vascular formada oferece um suprimento metabólico suficiente ao embrião.

A vascularização da membrana vitelina (MV) dos embriões de codorna sofreu interferência da quantidade e qualidade da suplementação com PUFA oferecida às aves ao longo do processo de incubação (Fig. 2).

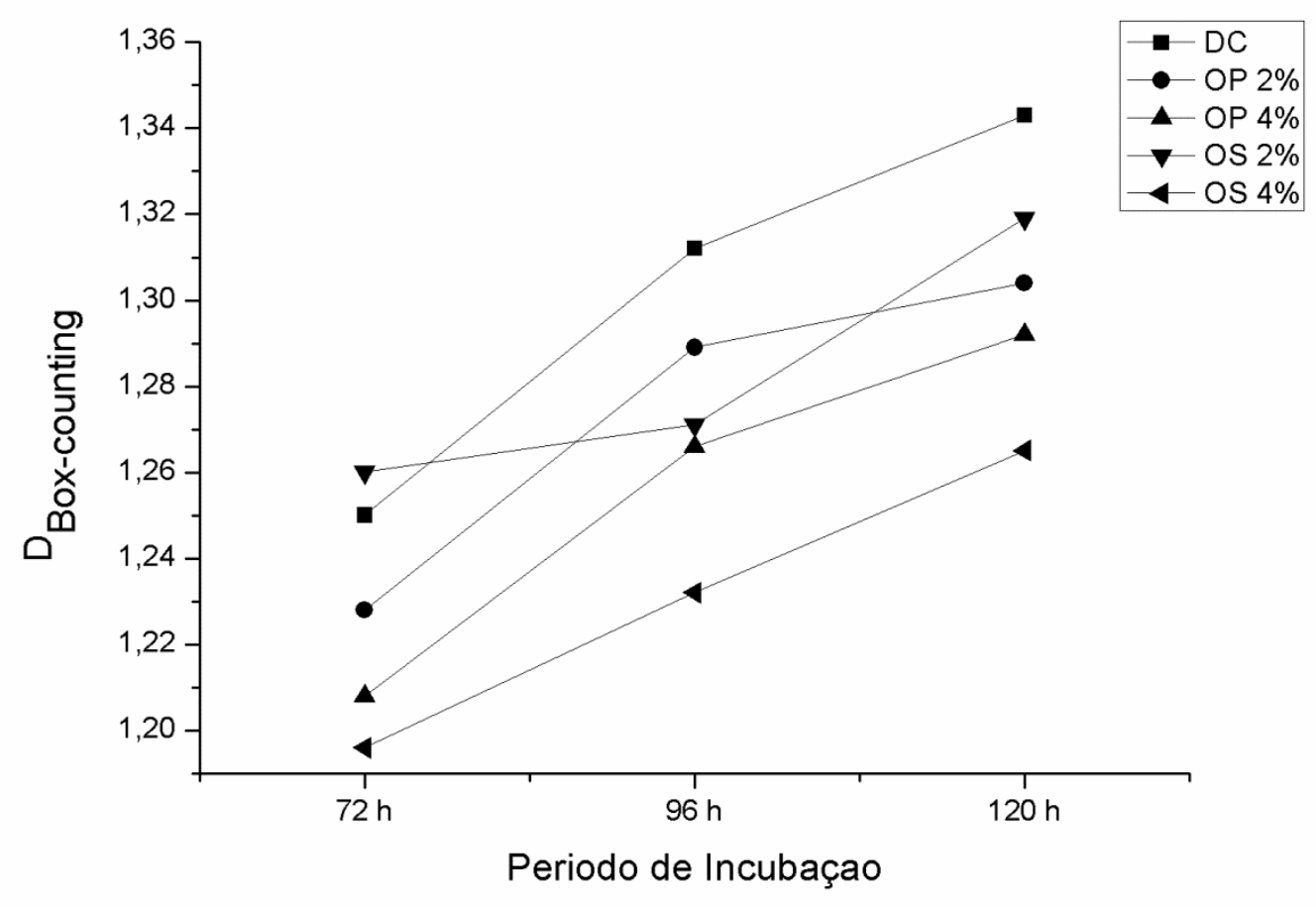

Figura 2. Comportamento da dimensão fractal $\left(\mathrm{D}_{b c}\right)$ da vascularização da MV em 72, 96 e 120 horas de incubação para os grupos experimentais. 
Existe uma relação entre a fonte de ácido graxo da dieta e o metabolismo dos lipídios, observada por alterações nos perfis lipídicos, como os níveis séricos de colesterol, HDL e triglicerídeos. Esta relação também pode ser observada no perfil lipídico do vitelo, uma vez que a composição dos ácidos graxos no ovo é marcadamente influenciada pelo tipo de lipídio presente na dieta. Em codornas japonesas, a suplementação com $4 \%$ de óleo de peixe e $4 \%$ de óleo de soja promoveu aumento siginificativo nas concentrações de ômega-3 do vitelo de codornas japonesas, entre eles, os ácidos eicosapentaenoico (EPA) e docosahexaenoico (DHA), em relação à suplementação em niveis semelhantes de outras fontes lipídicas, como óleo de girassol e óleo de oliva (GÜÇLÜ et al., 2008).

O vitelo, por sua vez, é de fundamental importância, pois possui o material nutritivo que irá sustentar o desenvolvimento do embrião, sendo a fonte de vitaminas lipossolúveis, ácidos graxos e energia. Neste estudo, uma inibição do crescimento vascular ocorreu na MV dos embriões de codornas que receberam maiores concentrações de PUFA n-3 e n-6. Durante o desenvolvimento embrionário, os lipídios e os componentes associados são transferidos da gema para a MV por fagocitose. Nessa membrana, por sua vez, ocorrem a vasculogênese e a angiogênese, que são diretamente influenciadas pelo tipo de ácido graxo poliinsaturado, como proposto por Halbe e Cunha (2008), entre eles o EPA e o DHA.

A membrana vitelina, assim como a membrana corioalantoide, mostra-se um modelo experimental adequado para o estudo das alterações dos padrães vasculares, principalmente no que se refere à formação inicial da árvore vascular (vasculogênese). Além disso, a análise fractal se apresenta como um método matemático confiável para a quantificação do crescimento vascular em modelos in vivo como a membrana vitelina, como anteriormente observado por outros autores utilizando a membrana corioalantoide e outros modelos biológicos.

\section{CONCLUSÕES}

A adição de PUFA n-3 e n-6 na ração não alterou o nível sérico de colesterol total das codornas. Aumento no nível sérico de colesterol HDL foi observado no grupo tratado com $4 \%$ de óleo de peixe. A suplementação com óleo de peixe elevou os níveis de triglicerídeos das aves em relação aos demais tratamentos. Embora estudos apontem que o uso de PUFA não altere os níveis de colesterol do ovo, a adição de n-3 e n-6 em $4 \%$ reduziu a vascularização da MV dos embriões. Isto pode ser resultante da alteração da composição lipídica dos PUFA no vitelo, os quais interferem no processo de formação vascular e, consequentemente, podem interferir no desenvolvimento embrionário.

\section{AGRADECIMENTOS}

À Netuno Alimentos S/A, pela doação do óleo de peixe. À EEPAC/ UFRPE, pela doação das aves. À FACEPE, pela concessão de bolsa de pósgraduação. Ao Centro de Apoio à Pesquisa (CENAPESQ) - UFRPE, pela utilização dos laboratórios multiusuários. Ao Programa de PósGraduação em Biociência Animal (PPGBA) UFRPE, pela liberação de auxílio para pesquisa.

\section{REFERÊNCIAS}

AVAKIAN, A.; KALINA, R.E.; SAGE, E.H. et al. Fractal analysis of region-based vascular change in the normal and non-proliferative diabetic retina. Curr. Eye Res., v.24, p.274-280, 2002.

BASSINGTHWAIGHTE, J.B.; LIEBOVITCH, L.S.; WEST, B.J. Fractal physiology. New York: Oxford University, 1994. 364p.

CALDER, P.C. Effects of fatty acids and dietary lipids on cells of the immune system. Proc. Nutr. Soc., v.55, p.127-50, 1996.

CALDER, P.C. Long-chain n-3 fatty acids and inflammation: potential application in surgical and trauma patients. Braz. J. Med. Biol. Res., v.36, p.433-446, 2003.

CIANCHI, F.; CORTESINI, C.; FANTAPPIÈ, O. et al. Inducible nitric oxid synthase expression in human colorectal cancer. Am. J. Pathol., v.162, p.793-801, 2003. 
CIANCHI, F.; CORTESINI, C.; FANTAPPIÈ, O. et al. Ciclooxygenase- 2 activation mediates the proangiogenic effect of nitric oxid in colorectal cancer. Clin. Cancer Res., v.10, p.2694-2704, 2004.

CHUNG, W.S.; LAI, K.M.; HSU, K.C. Comparative Study on Histological Structures of the Vitelline Membrane of Hen and Duck Egg Observed by Cryo-Scanning Electron Microscopy. J. Agric. Food Chem., v.58, p.17941799, 2010.

CONWAY, E.M.; COLLEN, D.; CARMELIET, P. Molecular mechanisms of blood vessel growth. Cardiovasc. Res., v.49, p.507-512, 2001.

DEWAILLY, E.; BLANCHET, C.; LEMIEUX, S. et al. N-3 fatty acids and cardiovascular disease risk factors among the Inuit of Nunavik. Am. J. Clin. Nut., v.74, p.464-473, 2001.

DEWAILLY, E.; BLANCHET, C.; GINGRAS, S. et al. Fish comsumption and blood lipids in three ethnic groups of Québec (Canada). Lipids, v.38, p.359-365, 2003.

FANCHIOTTI, F.E.; MORAES, G.H.K; BARBOSA, A.A. et al. Avaliação de óleos, carvão vegetal e vitamina $E$ no desempenho e nas concentrações lipídicas do sangue e dos ovos de poedeiras. Rev. Bras. Zootec., v.39, p.26762682, 2010.

GÜÇLÜ, B.K.; UYANIK, F; İŞCAN, K.M. Effects of dietary oil sources on egg quality, fatty acid composition of eggs and blood lipids in laying quail. S. Afr. J. Anim. Sci., v.38, p.91-100, 2008.

HALBE, H.W.; CUNHA, D.C. O excesso do órgão adiposo. Diagn. Tratamento, v.13, p.153160, 2008.

HARRIS, W.; MOZAFFARIAN, D.; RIMM, E. et al. Omega-6 fatty acids and risk for cardiovascular disease: a science advisory from the American Heart Association, Nutrition Subcommittee of the Council on Nutrition, Physical Activity and Metabolism; Council on Cardiovascular Nursing; and Council on Epidemiology and Prevention. Circulation, v.119, p.902-907, 2009.

HENDRIX, M.J.C.; SEFTOR, E.A.; HESS, A.R. et al. Vasculogenic mimicry and tumour-cell plasticity: lessons from melanoma. Nat. Rev. Cancer, v.3, p.411-442, 2003.
KUNICKI, A.C.B; OLIVEIRA, A.J.; MENDONÇA, M.B.M. et al. Can the fractal dimension be applied for the early diagnosis of nonproliferative diabetic retinopathy? Braz. J. Med. Biol. Res., v.42, p.930-934, 2009.

MANDELBROT, B.B. Objetos fractais. Lisboa: Gradiva. 1991. 296p.

MENDONÇA JR., C.X.; MARTINS, A.P.; MORI, A.V. et al. Efeito da adição de óleo de peixe à dieta sobre o desempenho e níveis de lipídios plasmáticos e de colesterol no ovo de galinhas poedeiras. Braz. J. Vet. Res. Anim. Sci., v.37, 2000. Disponível em: <http://www.scielo.br/scielo.php> Acessado em: 21 maio. 2012.

MOLENA-FERNANDES, C.A.; SCHIMIDT, G.; NETO-OLIVEIRA, E.R. et al. Avaliação dos efeitos da suplementação com farinha de linhaça (Linum usitatissimum L.) marrom e dourada sobre o perfil lipídico e a evolução ponderal em ratos Wistar. Rev. Bras. Pl. Med., v. 12, p. $201-$ 207, 2010.

MOURA, A.M.A.; FONSECA, J.B.; TAKATA, F.N. et al. Determinação da energia metabolizável de alimentos para codornas japonesas em postura. Arq. Bras. Med. Vet. Zootec., v.62, p.178-183, 2010.

MURATA, L.S.; ARIKI, J.; MACHADO, C.R. et al. Effect of Oils Sources on Blood Lipid Parameters of Commercial Laying Hens. Braz. J. Poult. Sci., v.5, p.203-206, 2003.

NARAYANAM，B.A.; NARAYANAM， N.K.; SIMI, B. et al. Modulation of inducible nitric oxide synthase and related proinflammatory genes by the omega- 3 fatty acid docosahexaenoic acid in human colon cancer cells. Cancer Res., v.63, p.972-975, 2003.

NATIONAL research concil-NRC. Nutrient Requeriments of Poult. 9.ed. Washington, D.C.:National Academy of Sciences, 1994. 44$45 \mathrm{p}$.

NAVIDSHAD, B; DELDAR, H; POURRAHIMI, G. Correlation between serum lipoproteins and abdominal fat pad in broiler chickens. Afr. J. Biotechnol., v.9, p.5779-5783, 2010.

O'SHEA, M.; BASSAGANYA-RIERA, J.; MOHEDE, I.C. Imunomodulatory properties of conjugated linoleic acid. Am. J. Clin. Nut., v.79, p.1199S-1206S, 2004. 
PARSONS-WINGERTER, P.; LWAI, B.; YANG, M.C. et al. A novel assay of angiogenesis in the quail chorioallantoic membrane: stimulation by bFGF and inhibition by angiostatin according to fractal dimension and grid intersection. Microvasc. Res., v.55, p.201214, 1998.

PEREIRA, C.A.; BARRETO, S.L.T.; ROSTAGNO, H.S. Desempenho de codornas japonesas alimentadas com dietas contendo diferentes níveis de cálcio durante o pico de postura. In: REUNIÃO ANUAL DA SOCIEDADE BRASILEIRA DE ZOOTECNIA, 41., 2004, Campo Grande. Anais... Campo Grande: Sociedade Brasileira de Zootecnia, 2004.

RABER, M.R.; RIBEIRO, A.M.L; KESSLER, A.M. et al. Desempenho, metabolismo e níveis plasmáticos de colesterol e triglicerídeos em frangos de corte alimentados com óleo ácido e óleo de soja. Cienc. Rural, v.38, p.1730-1736, 2008.
SHENG, G. Primitive and definitive erythropoiesis in the yolk sac: a bird's eye view. Int. J. Dev. Biol., v.54, p.1033-1043, 2010.

TOTH, P. High-density lipoprotein and cardiovascular risk. Circulation, v.109, p.1809$1812,2004$.

VICO, P.G.; KYRYACOS, L.; HEYMANS, O. et al. Dynamic Study of the Extraembryonic Vascular Network of the Chick Embryo by Fractal Analysis. J. Theor. Biol., v.195, p.525532, 1998. 